\title{
Cystic fibrosis: current treatment and future direction
}

\author{
Shreya Gupta*, Niti Mittal, Mahesh C. Gupta
}

Department of Pharmacology, Pt. BD Sharma, PGIMS Rohtak, Haryana, India

Received: 23 January 2021

Revised: 28 February 2021

Accepted: 02 March 2021

*Correspondence:

Dr. Shreya Gupta,

Email: em.shreya@gmail.com

Copyright: ( $)$ the author(s), publisher and licensee Medip Academy. This is an open-access article distributed under the terms of the Creative Commons Attribution Non-Commercial License, which permits unrestricted non-commercial use, distribution, and reproduction in any medium, provided the original work is properly cited.

\begin{abstract}
Cystic fibrosis is an autosomal recessive genetic disorder, characterized by mutation in the cystic fibrosis transmembrane conductance regulator (CFTR) gene, leading to abnormality in the chloride channels of the mucus and sweat producing glands. Multiple organs systems are affected in this disorder, like respiratory system and gastrointestinal tract, severely impacting the patient's quality of life, eventually leading on to several complications and death. Since the uncovering of the underlying genetic defect in cystic fibrosis (CF), our knowledge of the disease process has increased substantially, but we still lack a holistic approach to its management, which comprises of multiple facades, requiring both pharmacological and non-pharmacological or rehabilitatory approaches. So far, the therapeutic options were limited to targeting the consequences and complications of the disease, such as respiratory infection, mucus retention, pancreatic insufficiency, etc., but now several promising therapies may be able to address the underlying pathology rather than its long-term effects. This review summarizes the current and upcoming pharmacological options for CF, such as those targeting the CFTR gene defect directly, including gene editing, CFTR correctors and potentiators; drugs targeting the epithelial sodium channels ( $\mathrm{ENaC}$ inhibitors); repositioning of some existing drugs and evaluating their role in CF; and understanding the disease better by transcriptomic approaches and the role of gut microbiota in the disease process and severity.
\end{abstract}

Keywords: Cystic fibrosis, CFTR, Chloride ion channels, Sodium epithelial channels

\section{INTRODUCTION}

Cystic fibrosis (CF) is a progressive, autosomal recessive disorder characterised by severe damage to the various mucus, sweat and digestive juices secreting organs, such as lungs, sweat glands and pancreas, and currently affects more than 30,000 individuals in the United States. With an incidence of 1 in 3400 live births, about 900-1000 new cases of CF are diagnosed each year in US. Although CF is common in people of all races and ethnicity, it is most commonly diagnosed in Caucasians, with one in every 29 individuals a carrier of the $\mathrm{CF}$ gene mutation. ${ }^{1-3}$

The gene defect in $\mathrm{CF}$ is in the cystic fibrosis transmembrane conductance regulator (CFTR), which functions as a chloride ion trafficker in the plasma membrane of the epithelial cells of pancreas, liver, intestines, epididymis, sweat glands and lungs. Adequate chloride transport across ion channels helps maintain the movement of water in tissues, necessary for production of thin, free flowing mucus. Normal CFTR protein is exported from the endoplasmic reticulum (ER) to the Golgi apparatus for further processing, following which it gets transported to the cell membrane of acinar and other epithelial cells, where it regulates sodium and chloride ion transportation, thereby modulating the composition and amount of exocrine glands' secretion. It encodes an adenosine triphosphate gated chloride channel, which has different roles in different organ systems. CFTR aids in chloride secretion in the lungs and gastrointestinal tract, whereas it promotes the reabsorption of chloride in sweat glands. Failure or disruption of this mechanism causes 
inadequately hydrated mucus and abnormal transport of glandular secretions, which is the major cause of ductal obstruction, proceeded by tissue injury and/or infections. ${ }^{1,4,5}$

Since CF is an autosomal recessive disorder, mutations in both copies of CFTR gene is required to cause the disease. CFTR gene is located on chromosome 7 and more than 1900 mutations have been identified, out of which F508 deletion is the most common mutation, causing deletion of 3 bases for phenylalanine at the $508^{\text {th }}$ position. ${ }^{1,3}$ In the advent of a mutation like F508, a misfolded CFTR protein is produced, which after being recognised by the ER is degraded in the cytoplasm. Even if some amount of protein does reach the plasma membrane, its half-life is significantly reduced as compared to the wild type CFTR. ${ }^{1,5,6}$ Other mutations like G542X, W1282X cause the production of non-functional protein; G551D, S549N mutations cause improper channel opening, and D1152H, R347P cause faulty channel functioning. ${ }^{5,6}$

CFTR is also known to cause abnormal airway fluid composition, by altering the $\mathrm{pH}$, and may directly mediate inflammatory responsiveness, causing pulmonary remodelling and persistent inflammation. ${ }^{1}$

Cystic fibrosis affects multiple organ systems at once, causing a myriad of complications with increasing severity of the disease. Some of the respiratory complications include, recurrent pulmonary infections ( $S$. aureus in childhood, $P$. aeruginosa in adulthood), bronchiectasis, chronic bronchitis, nasal polyps, haemoptysis, leading on to respiratory failure. $\mathrm{CF}$ can also cause pancreatic insufficiency causing malabsorption of fat and fat-soluble vitamins (A, D, E, K), hepatic dysfunction leading on to cirrhosis, intestinal obstruction, gall stones, intussusception, meconium plugging in newborns. Infertility in males (absence of vas deferens) and subfertility in females (amenorrhea, thick cervical mucus) is also possible. Other systemic complications include osteoporosis, dehydration, electrolyte imbalance, weakness, fatigue, low blood pressure. ${ }^{1,4}$

The diagnosis of CF is mostly made by 2 years of age in 75 percent of the population, but some individuals may not be diagnosed until adulthood. Diagnosis of CF can be made by: new born screening, which detects infants having high level of immuno-reactive trypsin in their blood, it may be combined with genetic testing to determine the exact mutation, genetic testing is also recommended for CF carrier couples; sweat test, for carrying out abnormally high chloride levels measurement; and trans-epithelial nasal lining testing, which may be used as a confirmatory test in which more negative trans epithelial potential difference across nasal epithelium is seen in diseased individuals. $^{7}$

Goals of treatment include, improvement of the general health of the patient with adequate calorie intake, maintenance of normal weight, use of nutritional supplements orally, or via feeding tube, adequate salt intake, oral vitamins and enzyme intake. ${ }^{8}$ Maintenance of pulmonary health is important, by controlling lung infections, limiting airway inflammation, reducing and removing thick mucus and airway dilatation. Airway clearance therapy (ACT) has also proven useful in which, daily manual chest physiotherapy is done by using a device called the "VEST" which is a jacket that shakes the mucus plugged in the airways, enabling one to cough it up. ${ }^{9}$ Prevention of intestinal blockage can be done by prescribing osmotic laxatives, oral rehydration and enema. Any pancreatic insufficiency can be overcome by pancreatic enzyme replacement therapy (PERT) containing combinations of proteases, lipases and amylases. $^{10}$

\section{Current pharmacotherapy of CF}

Main focus of therapy in $\mathrm{CF}$ is on the correction of structural and functional abnormalities of the altered CFTR protein. CFTR modulators are being used for this purpose, some of which are: ivacaftor, lumacaftor, elexacaftor and tezacaftor, available as monotherapy or in combination with one another.

Ivacaftor was the first targeted drug approved by Food and Drug Administration (FDA) in 2012. It is indicated for use in children $\geq 6$ years with $C F$, having at least one G551D mutation. Ivacaftor opens the number and duration $\mathrm{Cl}-$ channel opening, thus improving chloride transport. In patients having G551D mutation, the location of the channel is proper but function is impaired, preventing the trans-conductance of chloride and fluid. But since the mutation drug targets is rarer than F508del (2.3\% patients only), it targets only a small proportion of the affected population. Also high cost of therapy is a limiting factor. ${ }^{11}$

Lumacaftor is currently approved as a combination therapy with ivacaftor, under the brand name Orkambi. The two drugs work together to restore and enhance the function of the CFTR channel protein at the cell membrane. Lumacaftor works by correcting the misfolded proteins and improving their transport to the cell surface. But since it does not increase time of channel opening, lumacaftor is used in combination with ivacaftor to provide additive effects. ${ }^{12}$

Elexacaftor and tezacaftor have been approved by USFDA in October 2019 as a combination therapy with ivacaftor under the brand name Trikafta. This combination is indicated for individuals $\geq 12$ years with F508del mutation. Trikafta also received orphan drug and breakthrough therapy status from FDA. Elexacaftor is a CFTR corrector, which causes degradation of the faulty protein by targeting its processing defect. This in turn increases the amount of corrected protein that reaches the cell membrane. Tezacaftor is also a CFTR corrector.

It functions by correcting the position of CFTR protein on the cell surface and permits proper channel formation, to 
improve the flow of ions and water. This drug is also available in combination with ivacaftor alone, under the brand name Symdeko. ${ }^{13-15}$

Although CFTR modulators have significantly improved treatment of $\mathrm{CF}$, there are still some possible limitations, some of which include, lack of significant response in individuals heterozygous for F508del, myriad of side effects of the present drugs like elevated liver enzymes, upper respiratory tract infections, cataract etc., need for prolonged symptomatic treatment on a daily basis, need for high doses of CFTR modulators and negligible use in children $<12$ years old. ${ }^{5}$

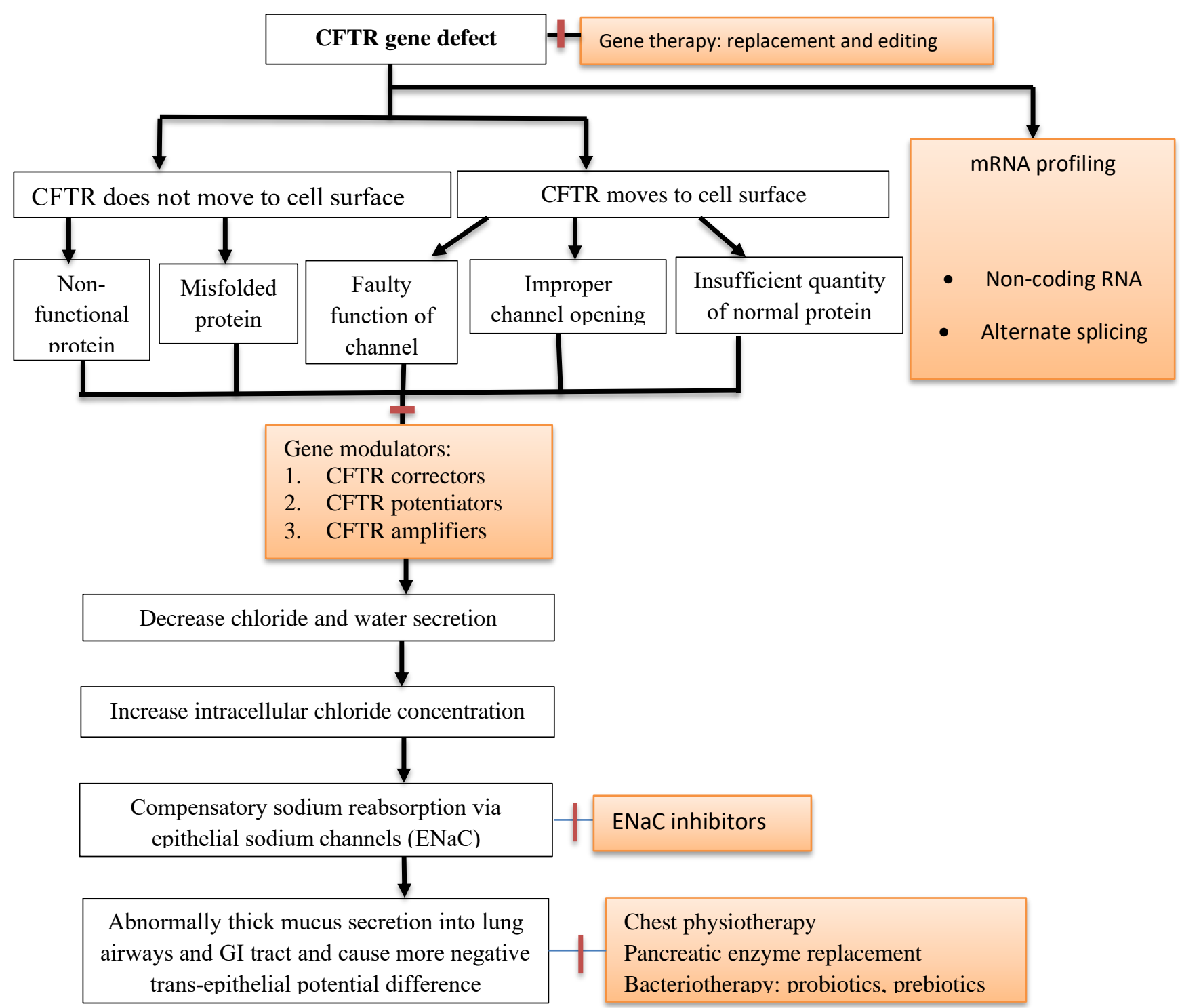

Figure 1: Potential drug targets for CF.

\section{TARGETING GENE DEFECT}

\section{Gene replacement therapy}

CFTR gene was discovered in 1989, since then gene replacement therapy is being actively researched as a onetime treatment in CF patients; i.e. replacing the mutated gene with a functional copy. But this approach has not yielded any promising results. One major barrier is the lack of efficient vectors that can deliver functional CFTR gene without having immunological consequences. ${ }^{16}$

\section{Gene editing}

Gene editing approaches are also being tried, by using nucleases to enzymatically correct the mutated genes in the naïve cell. One of the most promising tool in today's scenario is the CRISPR/Cas9 technology (Figure 2), which used RNA-protein complex composed of Cas9 enzyme, which binds to a guide RNA, to identify the target DNA 
sequence. Repair of CFTR locus in human intestinal cells has been tried, which was successful in restoring CFTR function. While this technology also faces risk of off-target insertion, it shows great promise. ${ }^{17}$

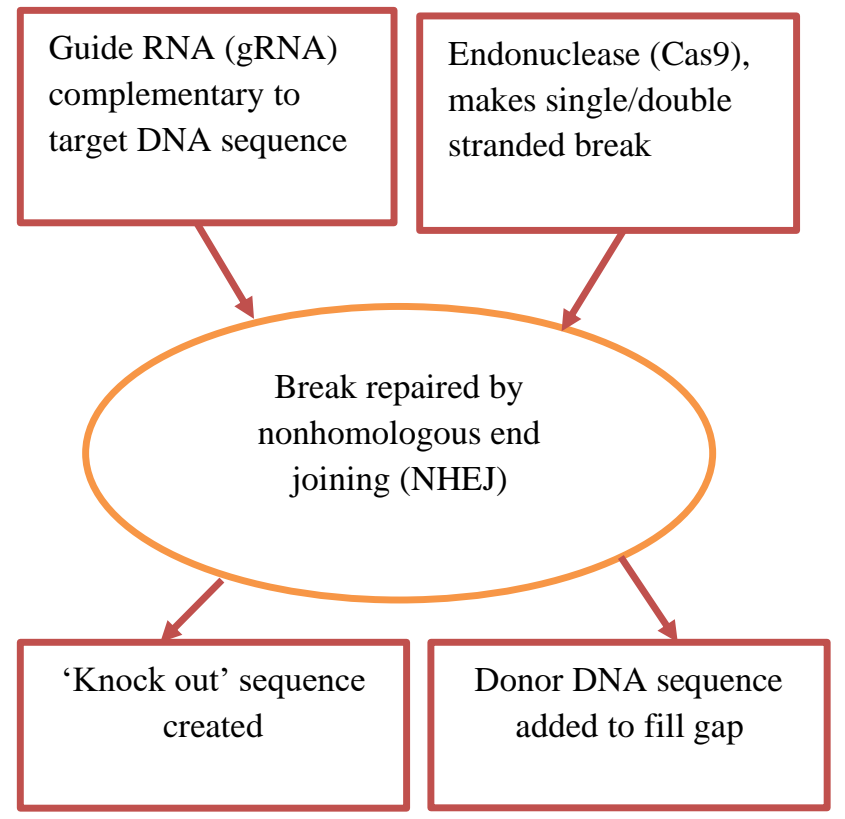

Figure 2: Gene editing approach using CRISPR/Cas9 technology.

Since, gene therapy has limited options in the current treatment of $\mathrm{CF}$, it becomes important to understand the basic CFTR defects and identify novel molecular markers.

\section{TARGETING CFTR}

Many other molecules having CFTR corrector potential are currently under trial (Table 1).

\section{DRUG REPOSITIONING IN CF}

Repositioning of existing drugs that are already in use for other diseases is an emerging concept in drug discovery programs. In this proof-of-concept studies are carried out as novel drug targets in rare diseases which are lacking effective treatment options. Repurposed drugs offer cost and time saving alternatives as most of them already have sufficient safety and toxicological data available. Thus, many other small molecule entities targeting CF associated genes are under trials. ${ }^{25}$ Some of these are discussed in the Table 2.

\section{TARGETING ENaC}

Epithelial sodium channels $(\mathrm{ENaC})$ are another important group of channels which are constantly working in opposition or in synchronization with the CFTR protein channels, depending upon the organ specific epithelial lining. $\mathrm{ENaC}$ is a heteromeric protein, composed of 3 homologous subunits $(\alpha, \beta$, and $\gamma)$. In the lungs CFTR defect causes retention of intracellular chloride, which in turn causes sodium and water reabsorption via ENaC channels, thus contributing to thick and viscous airway secretions.

Based on this hypothesis, $\mathrm{ENaC}$ is being considered as a novel therapeutic target, and its inhibition is theorized to increase hydration of mucus and enhance muco-ciliary transport in $\mathrm{CF}$ experimental models. ${ }^{37}$ Current ENaC directed research are included in Table 3.

However, controversy still exists regarding the exact relationship between CFTR and ENaC. Recent efforts have been made to engineer designer drugs, producing long lasting $\mathrm{ENaC}$ inhibition in the airways, and while some of these molecules show promise, several ENaCtargeted therapeutics have failed in the clinical trials, despite showing promising pre-clinical results. ${ }^{38}$

Table 1: Drugs targeting CFTR protein.

\begin{tabular}{|c|c|c|}
\hline $\begin{array}{l}\text { Mechanism of } \\
\text { action }\end{array}$ & New entity & Stage of development \\
\hline \multirow{2}{*}{ CFTR corrector } & FDL169 & Phase $\mathrm{I} 1^{8}$ \\
\hline & Galicaftor (GLPG2222) & Phase II $^{19}$ \\
\hline CFTR potentiator & RPL554 & Phase II $^{20}$ \\
\hline \multirow{3}{*}{ CFTR amplifier } & $\begin{array}{l}\text { Nesolicaftor (PTI428): acts to increase the amount of protein } \\
\text { produced }\end{array}$ & Phase $\mathrm{I}^{21}$ \\
\hline & $\begin{array}{l}\text { Ataluren (PTC124): partially restore CFTR production in animals } \\
\text { with a nonsense mutation }\end{array}$ & Phase II $^{22}$ \\
\hline & $\begin{array}{l}\text { MRT5005: delivers corrected copies of CFTR-encoded mRNA to } \\
\text { lungs }\end{array}$ & Phase $\mathrm{I} / \mathrm{II}^{23}$ \\
\hline $\begin{array}{l}\text { Eukaryotic } \\
\text { ribosomal selective } \\
\text { glycoside (ERSG) }\end{array}$ & $\begin{array}{l}\text { ELX-02: increases read-through activity in case of nonsense } \\
\text { mutations, to enable the production of full-length functional CFTR } \\
\text { protein }\end{array}$ & Phase II $^{24}$ \\
\hline
\end{tabular}


Table 2: Drug repositioning in $\mathrm{CF}$.

\begin{tabular}{|c|c|c|}
\hline Drug & Class & Postulated mechanism/target \\
\hline Doxycycline $^{26}$ & \multirow{9}{*}{$\begin{array}{l}\text { Small } \\
\text { molecule }\end{array}$} & $\begin{array}{l}\text { Inhibits matrix metalloproteinase (MMP) } 1,7,8,9,13 \text {, associated with the } \\
\text { severity of lung disease in } \mathrm{CF}\end{array}$ \\
\hline Cholecalciferol $^{27}$ & & $\begin{array}{l}\text { Nuclear hormone receptor VDR agonist. } \\
\text { Causes immune system modulation. Affects function and signalling of T cell } \\
\text { populations by downregulating toll like receptor (TLR) expression. Also } \\
\text { promotes hypo-responsiveness to pathogen associated molecular patterns } \\
\text { (PAMPs), reducing co-stimulatory molecule and MHC II expression in antigen } \\
\text { presenting cells }\end{array}$ \\
\hline Denufosol $^{28}$ & & $\begin{array}{l}\text { Purine receptor agonist, novel ion channel regulator shown to correct ion } \\
\text { transport and increase mucociliary, ciliary beat frequency of airway epithelium }\end{array}$ \\
\hline Prednisone $^{29}$ & & $\begin{array}{l}\text { Nuclear hormone receptor NR3C1 agonist. } \\
\text { Proposed as an adjuvant to limit pulmonary exacerbations. }\end{array}$ \\
\hline Nitric oxide ${ }^{30}$ & & $\begin{array}{l}\text { Soluble guanylate cyclase agonist. } \\
\text { proposed to increase chloride channels by activating CFTR and alternative } \\
\text { chloride channels }\end{array}$ \\
\hline Sildenafil $^{31}$ & & $\begin{array}{l}\text { Increases blood flow and endothelial function, contributing to exercise } \\
\text { intolerance, improves quality of life of patients }\end{array}$ \\
\hline Digitoxin $^{32}$ & & $\begin{array}{l}\text { Hydrolase antagonist } \\
\text { ATP1A1, ATP1A2 ATP1B3. } \\
\text { Suppresses hypersecretion of IL-8 from lung epithelium }\end{array}$ \\
\hline Omeprazole ${ }^{33}$ & & $\begin{array}{l}\text { APT4B antagonist. } \\
\text { Proposed as an adjunct to pancreatic enzyme replacement therapy (PERT) to } \\
\text { improve dietary fat absorption }\end{array}$ \\
\hline Miglustat $^{34}$ & & $\begin{array}{l}\text { Transferase antagonist } \\
\text { Propped to normalize nasal potential difference (NPD) in F508del patients }\end{array}$ \\
\hline $\begin{array}{l}\text { Interferon gamma } \\
1 B^{35}\end{array}$ & \multirow[b]{2}{*}{ Protein } & $\begin{array}{l}\text { Membrane receptor IFNGR1, IFNGR2 agonist. } \\
\text { Proposed to enhance lung function }\end{array}$ \\
\hline Insulin glargine ${ }^{36}$ & & $\begin{array}{l}\text { INSR agonist } \\
\text { Evaluated for beneficial effects on BMI, acute pulmonary infections, lung } \\
\text { function, and } \mathrm{HbA} 1 \mathrm{c}\end{array}$ \\
\hline
\end{tabular}

Table 3: ENaC targeting drugs in CF.

\begin{tabular}{|c|c|c|c|}
\hline Mechanism & Drug & Class & Stage of development \\
\hline \multirow{5}{*}{ Direct inhibition } & NVP-QBE 170 & \multirow{7}{*}{ Small molecule } & Pre-clinical ${ }^{38}$ \\
\hline & AZD 5634 & & Phase $\mathrm{I}^{39}$ \\
\hline & VX 371 & & Phase $\mathrm{II}^{40}$ \\
\hline & QBW276 & & Phase I/II ${ }^{41}$ \\
\hline & BI 443651 & & Phase $I^{42}$ \\
\hline \multirow[b]{2}{*}{$\begin{array}{l}\text { Channel activating } \\
\text { protease inhibitor }\end{array}$} & QUB-TLI & & Pre-clinical ${ }^{43}$ \\
\hline & MK 104 & & $\begin{array}{l}\text { Pre-clinical } \\
\text { (abstract in Hall R. J Cyst Fibros. } \\
2016 ; 15: 4-5)\end{array}$ \\
\hline \multirow{3}{*}{ Molecular inhibition } & $\mathrm{ARO} \mathrm{ENaC}$ & \multirow[t]{2}{*}{ Small interfering RNA } & $\begin{array}{l}\text { Pre-clinical (abstract in Am J Respir Crit } \\
\text { Care Med. 2018;197:A3867) }\end{array}$ \\
\hline & siRNA & & Pre-clinical ${ }^{44}$ \\
\hline & ENaC Inhibitory ASO & Oligonucleotide & Pre-clinical $^{45}$ \\
\hline $\begin{array}{l}\text { ENaC channel } \\
\text { internalization }\end{array}$ & SPX 101 & Peptide analogue & Phase $\mathrm{II}^{46}$ \\
\hline
\end{tabular}

While the concept of ENaC targeted drugs shows promise, researchers are yet to overcome several challenges associated with these drugs.

For example, it is important to limit its targeted effects to the lungs, while sparing the off target and systemic effects.
Prolonged duration of action is needed for more compliant dose regime, along with determining the optimal time for induction of therapy in the disease course, with respect to disease onset. Our understanding of the complementary effects of CFTR and ENaC is still limited, which needs to be expanded for better utilization of such novel therapies. 


\section{TARGETING TRANSCRIPTOME}

Transcriptome is the study and identification of all the messenger RNA (mRNA) expressed by an organism. Transcriptome profiling has emerged as a valuable tool in understanding the genetic regulation of a particular cell lineage, and is being used to understand pathophysiologic basis of many disease, including cystic fibrosis.

With gene replacement and gene editing approaches still in their infancy, transcriptome analysis have emerged as robust tools, with potential of determining phenotypic variability and providing novel molecular targets. ${ }^{47}$

Microarray and RNA-sequencing are two important transcriptome profiling technologies that have proven powerful in deducing and quantifying transcriptomes in many CF studies. Microarray techniques are based on hybridization and focus on quantifying a predefined set of transcripts, whereas RNA-sequencing is sequence-based and performs an unbiased quantification of all transcripts within a cell even without prior knowledge of a particular gene. RNA-sequencing can also provide information on alternative splicing and sequence variation in the targeted genes. $^{47}$

\section{Non-coding RNAs}

Non-coding RNAs (ncRNAs) have a crucial role in regulation of gene expression and various biological processes. Although there are several types of ncRNAs, the two most studied species include: microRNAs (miRNAs) and long non-coding RNAs (lncRNAs). ${ }^{48}$

\section{miRNAs}

miRNAs are 20-25 nucleotides long, single stranded ncRNA sequences. Their role has been described in many cancers and respiratory diseases like asthma, chronic obstructive pulmonary disease, and $\mathrm{CF}$. In $\mathrm{CF}$, increased levels of miR-155 has been seen in the bronchial epithelial cells, which are also implicated in the increased expression of IL-8, a proinflammatory cytokine. Also. Altered expression of miR-126 has been associated with altered innate immune response in the airways in $\mathrm{CF}^{4}{ }^{48,49}$

\section{$\operatorname{lncRNAs}$}

lncRNAs are large, >200 nucleotide long ncRNA, which can act as activators or repressors of gene expression. They have the capacity to modify chromatin and regulate processes such as transcription and post transcriptional modifications. Abnormal expression of some lncRNAs have been suggested to play vital role lung infection and inflammation in CF patients. More specifically, a unique lncRNA profile was seen while analysing transcriptome sequences from $\mathrm{CF}$ and non-CF epithelial cells after being infected with $P$. aeruginosa. ${ }^{50}$

\section{Alternate splicing}

Alternative splicing is the mechanism through which mammalian genes generate distinct transcript isoforms, having diverse functions in different cell-types and disease states. Splicing is regulated by various splicing factors, encoding protein molecules that enable precise selection of splice sites, further carrying out the splicing process and protein synthesis. Transcriptome profiling enables us to quantify any alteration in the levels of splicing factors or transcript isoforms. A recent study carried out using neutrophils isolated from $\mathrm{CF}$ patients, identified 83 unique transcript isoforms which may be responsible for pulmonary exacerbations, providing us with some novel diagnostic and therapeutic targets. ${ }^{47,51}$

\section{TARGETING ALTERED GUT MICROBIOME}

A once fatal childhood disease, advances in the treatment of $\mathrm{CF}$ has since come a long way, leading to remarkable prolongation in the life expectancy of patients. However, increased longevity has led to new challenges, such as colorectal cancer (CRC). It has been seen that adenomatous polyps arising via the classical adenoma sequence, occur at a younger age in $\mathrm{CF}$ and are more aggressive in nature, associated with a worse prognosis in early stage of CRC. ${ }^{52}$ One of the causes of this early development of CRC is being attributed to altered gut microbiota composition and damaged microbiota-mucosal interface, causing chronic low grade mucosal inflammation in CF. In many experimental models, including clinical cohorts, altered gut microbiome composition has been demonstrated. Decreased diversity of microflora, temporal instability and decreased abundance of taxa such as Roseburia, Bifidobacterium, Faecalibacterium and Akkermansia has been seen. In the microbiome and fecal analysis carried out by Dayama et al, increased abundance of pathogenic bacterial species like as Clostridium and Fusobacteria, along with depletion of protective species like Ruminococcaceae was seen, which may facilitate the process of carcinogenesis. ${ }^{53}$

In an effort to correct dysbiosis, bacteriotherapy like probiotics and prebiotics may be tried in CF. several studies have been carried out with probiotics, particularly Lactobacillus $s p$. to observe their effects on the intestinal health of $\mathrm{CF}$ patients. Results of these studies are awaited. ${ }^{54}$

\section{CONCLUSION}

Cystic fibrosis is a complex, multifactorial genetic disorder, affecting thousands of children and adults worldwide. Accordingly, its management is also multidimensional, keeping into account the disease course and its symptomatic management on a daily basis. Although with the advent of disease specific CFTR modulators the management of $\mathrm{CF}$ patients has improved, no single corrector drug is potent enough to fix the multi domain structure and function of CFTR protein on its own. A 
combination of drugs having varied mechanisms of action, along with intensive physiotherapy is needed to curtail the disease progression and clinical symptoms. CF can have a myriad of genotypes and since most of the corrector drugs work on a particular genotype only, a large proportion of affected individuals are left with only symptomatic treatment options. Also most of these drugs have serious hepatotoxic potential and other side effects, in addition to high costs. Moreover, most of the molecules discussed above are still in early developmental or early clinical phase, with limited safety and efficacy data, and a lasting beneficial outcome cannot be guaranteed with any.

Due to the immense psychological and social burden of the disease, we need out-of-the-box approaches, by integrating genetic engineering and gene editing, with modern biological approaches like DNA nanotechnology, metabolomics, systems biology and intracellular protein kinetics.

Funding: No funding sources Conflict of interest: None declared

Ethical approval: Not required

\section{REFERENCES}

1. Ratjen FA. Cystic fibrosis: pathogenesis and future treatment strategies. Respir Care. 2009;54(5):595602.

2. American thoracic society. Cystic-fibrosis. Available at: $\quad$ https://www.thoracic.org/patients/patientresources/breathing-in america/resources/chapter-7cystic-fibrosis.pdf. Accessed on: 20 November 2020.

3. Cystic Fibrosis Foundation. About Cystic fibrosis. Available at: https://www.cff.org/What-is-CF/AboutCystic-Fibrosis/. Accessed on: 20 November 2020.

4. Rafeeq MM, Murad HAS. Cystic fibrosis: current therapeutic targets and future approaches. J Trans Med. 2017;15(1):84.

5. Guggino WB, Banks-Schlegel SP. Macromolecular interactions and ion transport in cystic fibrosis. Am J Respir Crit Care Med. 2004;170(7):815-20.

6. Mc Kone EF, Emerson SS, Edwards KL, Aitken ML. Effect of genotype on phenotype and mortality in cystic fibrosis: a retrospective cohort study. Lancet. 2003;361:1671-6.

7. American Lung Association. Cystic Fibrosis Symptoms and Diagnosis. Available at: https://www.lung.org/lung-health-and-diseases/lungdisease-lookup/cystic-fibrosis/diagnosing-andtreating-cf.html. Accessed on: 20 November 2020.

8. Borowitz D, Robinson KA, Rosenfeld M, Davis SD, Sabadosa KA, Spear SL, et al. Cystic Fibrosis Foundation evidence-based guidelines for management of infants with cystic fibrosis. J Pediatr. 2009;155(6):73-93.

9. Quan JM, Tiddens HA, Sy JP, McKenzie SG, Montgomery MD, Robinson PJ, Wohl ME, Konstan MW, Pulmozyme Early Intervention Trial Study Group. A two-year randomized, placebo-controlled trial of dornase alfa in young patients with cystic fibrosis with mild lung function abnormalities. J Pediatr. 2001;139(6):813-20.

10. Stern RC, Eisenberg JD, Wagener JS, Ahrens R, Rock M, Orenstein DM. A comparison of the efficacy and tolerance of pancrelipase and placebo in the treatment of steatorrhea in cystic fibrosis patients with clinical exocrine pancreatic insufficiency. Am J Gastroenterol. 2000;95(8):1932-8.

11. Condren ME, Bradshaw MD. Ivacaftor: a novel genebased therapeutic approach for cystic fibrosis. J Pediatr Pharmacol Ther. 2013;18(1):8-13.

12. Cystic Fibrosis News Today. Lumacaftor-VX 809. Available at: https://cysticfibrosisnewstoday.com /lumacaftor-vx-809/ Accessed on: 20 November 2020.

13. US Food and Drug Administration. FDA approves new breakthrough therapy for cystic fibrosis. Available at: https://www.fda.gov/news-events/pressannouncements/fda-approves-new-breakthroughtherapy-cystic-fibrosis. Accessed on: 20 November 2020.

14. Cystic Fibrosis News Today. Elexacaftor- VX 445. Available at: https://cysticfibrosisnewstoday.com /elexacaftor-vx-445/. Accessed on: 20 November 2020.

15. Cystic Fibrosis News Today. Tezacaftor-VX 661. Available at: https://cysticfibrosisnewstoday.com /tezacaftor-vx-661-for-cystic-fibrosis/. Accessed on: 22 November 2020.

16. Cooney AL, McCray PB, Sinn PL. Cystic fibrosis gene therapy: looking back, looking forward. Genes. 2018;9(11):538.

17. Roy B, Zhao J, Yang C, Luo W, Xiong T, Li Y, Fang $\mathrm{X}$, Gao G, Singh CO, Madsen L, Zhou Y. CRISPR/cascade 9-mediated genome editingchallenges and opportunities. Front gene. 2018;9:240.

18. US National Library of Medicine. A Study to Evaluate Safety, PK and PD of FDL169 in Cystic Fibrosis Subjects. Available at: https://clinicaltrials.gov/ct2/ show/NCT03093714. Accessed on 22 November 2020.

19. US National Library of Medicine. A Study to Evaluate Multiple Doses of GLPG2222 in Adult Subjects With Cystic Fibrosis. Available at: https://clinicaltrials.gov/ ct $2 /$ show/NCT03119649. Accessed on: 22 November 2020.

20. US National Library of Medicine. A Study of RPL554 in Patients With Cystic Fibrosis. Available at: https://clinicaltrials.gov/ct2/show/NCT02919995. Accessed on: 24 November 2020.

21. US National Library of Medicine. Study Assessing PTI-428 Safety, Tolerability, and Pharmacokinetics in Subjects With Cystic Fibrosis on KALYDECO® as Background Therapy. Available at: https://clinical trials.gov/ct2/show/NCT03258424. Accessed on: 24 November 2020.

22. US National Library of Medicine. PTC124 for the Treatment of Cystic Fibrosis. Available at: https://clinicaltrials.gov/ct2/show/NCT00351078. Accessed on: 24 November 2020. 
23. US National Library of Medicine. Study to Evaluate the Safety \& Tolerability of MRT5005 Administered by Nebulization in Adults With Cystic Fibrosis (RESTORE-CF). Available at: https://clinicaltrials. gov/ct2/show/NCT03375047. Accessed on: 24 November 2020.

24. US National Library of Medicine. Phase 2 Study to Evaluate the Safety, Tolerability, PK and PD of ELX02 in Cystic Fibrosis Patients With G542X Allele. Available at: https://clinicaltrials.gov/ct2/show /NCT04135495. Accessed on: 24 November 2020.

25. Tosco A, Villella VR, Castaldo A, Kroemer G, Maiuri L, Raia V. Repurposing therapies for the personalised treatment of cystic fibrosis. Expert Opinion on Orphan Drugs. 2018;6(6):361-73.

26. US National Library of Medicine. Trial of Doxycycline to Reduce Sputum MMP-9 Activity in Adult Cystic Fibrosis (CF) Patients (DOXY). Available at: https://clinicaltrials.gov/ct2/ show/NCT01112059. Accessed on: 24 November 2020.

27. Olszowiec-Chlebna M, Koniarek-Maniecka A, Brzozowska A, Błauż A, Rychlik B, Stelmach I. Vitamin D inhibits pro-inflammatory cytokines in the airways of cystic fibrosis patients infected by Pseudomonas aeruginosa-pilot study. Ital J Pediatr. 2019;45(1):41.

28. US National Library of Medicine. Study of Denufosol Tetrasodium Inhalation Solution in Patients with Cystic Fibrosis (CF) Lung Disease. Available at: https://clinicaltrials.gov/ct2/show/NCT00625612. Accessed on 24 November 2020.

29. US National Library of Medicine. Prednisone in Cystic Fibrosis Pulmonary Exacerbations (PIPE). Available at: https://clinicaltrials.gov/ct2/show /NCT03070522. Accessed on: 24 November 2020.

30. US National Library of Medicine. Efficacy and Safety of Inhaled Nitric Oxide (NO) in Cystic Fibrosis (CF) Patients. Available at: https://clinicaltrials.gov /ct2/show/NCT02498535. Accessed on: 26 November 2020.

31. US National Library of Medicine. Effects of Sildenafil on CFTR-dependent Ion Transport Activity. Available at: https:// clinicaltrials. gov/ct2/show/NCT01132482. Accessed on: 26 November 2020.

32. US National Library of Medicine. Phase II Study of Digitoxin to Treat Cystic Fibrosis. Available at: https://clinicaltrials. gov/ct2/show/ NCT00782288. Accessed on: 26 November 2020.

33. US National Library of Medicine. PPIs and Fat Absorption in $\mathrm{CF}$ and EPI. Available at: https://clinicaltrials.gov/ct2/show/NCT03551691. Accessed on: 26 November 2020.

34. US National Library of Medicine. Effect of Miglustat on the Nasal Potential Difference in Patients With Cystic Fibrosis Homozygous for the F508del Mutation (MIGLUSTAT-CF). Available at: https://clinicaltrials .gov/ct2/show/NCT02325362. Accessed on: 26 November 2020.
35. US National Library of Medicine. Interferon Gamma$1 \mathrm{~b}$ by Inhalation for the Treatment of Patients With Cystic Fibrosis. Available at: https://clinicaltrials.gov/ct2/show/NCT00043316. Accessed on: 26 November 2020.

36. US National Library of Medicine. One Year Glargine Treatment in CFRD Children and Adolescents. Available at: https://clinicaltrials.gov/ct2/show /NCT00483769. Accessed on: 30 November 2020.

37. Hanukoglu I, Hanukoglu A. Epithelial sodium channel $(\mathrm{ENaC})$ family: phylogeny, structure-function, tissue distribution, and associated inherited diseases. Gene. 2016;579(2):95-132.

38. Shei RJ, Peabody JE, Kaza N, Rowe SM. The epithelial sodium channel $(\mathrm{ENaC})$ as a therapeutic target for cystic fibrosis. Curr Opin Pharmacol. 2018;43:152-65.

39. Coote KJ, Paisley D, Czarnecki S, Tweed M, Watson H, Young A, et al. NVP-QBE170: an inhaled blocker of the epithelial sodium channel with a reduced potential to induce hyperkalaemia. Br J Pharmacol. 2015; 172:2814-26.

40. US National Library of Medicine. A Study to Assess the Effect of AZD5634 on Mucociliary Clearance, Safety, Tolerability and Pharmacokinetic Parameters in Patients With Cystic Fibrosis. Available at: https://clinicaltrials.gov/ct2/show/NCT02950805. Accessed on: 30 November 2020.

41. US National Library of Medicine. A Study to Evaluate the Safety and Efficacy of VX-371 in Subjects With Cystic Fibrosis Who Are Homozygous for the F508del-CFTR Mutation. Available at: https://clinicaltrials.gov/ct2/show/NCT02709109. Accessed on: 30 November 2020.

42. US National Library of Medicine Safety. Pharmacokinetics and Pharmacodynamics Study of Inhaled QBW276 in Patients With Cystic Fibrosis. Available at: https://clinicaltrials.gov/ct2/show/ NCT02566044. Accessed on: 30 November 2020.

43. US National Library of Medicine. BI 443651 Multiple Rising Dose in Healthy Volunteers Followed by a Cross-over in $\mathrm{CF}$ Subjects. Available at: https://clinicaltrials.gov/ct2/show/NCT02976519. Accessed on: 30 November 2020.

44. Reihill JA, Walker B, Hamilton RA, Ferguson TEG, Elborn JS, Stutts MJ, et al. Inhibition of ProteaseEpithelial Sodium Channel Signaling Improves Mucociliary Function in Cystic Fibrosis Airways. Am J Respir Crit Care Med. 2016;194:701-10.

45. Manunta MD, Tagalakis AD, Attwood M, Aldossary AM, Barnes JL, Munye MM, et al. Delivery of ENaC siRNA to epithelial cells mediated by a targeted nanocomplex: a therapeutic strategy for cystic fibrosis. Scientific Rep. 2017;7(1):1-2.

46. An Efficacy and Safety Study of SPX-101 Inhalation Solution in Subjects With Cystic Fibrosis ((HOPE-1)). Available at: https://clinicaltrials.gov/ct2/show /NCT03229252. Accessed on: 30 November 2020.

47. Ideozu JE, Zhang $\mathrm{X}$, McColley S, Levy $\mathrm{H}$. Transcriptome Profiling and Molecular Therapeutic 
Advances in Cystic Fibrosis: Recent Insights. Genes (Basel). 2019;10(3):180.

48. Glasgow AM, De Santi C, Greene CM. Non-coding RNA in cystic fibrosis. Biochem Soc. 2018;46(3):61930.

49. Stolzenburg LR, Harris A. The role of microRNAs in chronic respiratory disease: recent insights. Biol Chem. 2018;399(3):219-34.

50. Saayman SM, Ackley A, Burdach J, Clemson M, Gruenert DC, Tachikawa K, et al. Long non-coding RNA BGas regulates the cystic fibrosis transmembrane conductance regulator. Molecular Therapy. 2016;24(8):1351-7.

51. Jiang K., Poppenberg K.E., Wong L., Chen Y., Borowitz D., Goetz D., et al. RNA sequencing data from neutrophils of patients with cystic fibrosis reveals potential for developing biomarkers for pulmonary exacerbations. J Cyst Fibros. 2018.
52. Niccum DE, Billings JL, Dunitz JM, Khoruts A. Colonoscopic screening shows increased early incidence and progression of adenomas in cystic fibrosis. J Cyst Fibros. 2016;15:548-53.

53. Dayama G, Priya S, Niccum DE, Khoruts A, Blekhman R. Interactions between the gut microbiome and host gene regulation in cystic fibrosis. Genome Med. 2020;12(1):12.

54. US National Library of Medicine. Probiotics in Cystic Fibrosis. Available at: https://clinicaltrials.gov/ct2/ show/NCT01956916. Accessed on: 30 November 2020 .

Cite this article as: Gupta S, Mittal N, Gupta MC. Cystic fibrosis: current treatment and future direction. Int J Basic Clin Pharmacol 2021;10:44452. 